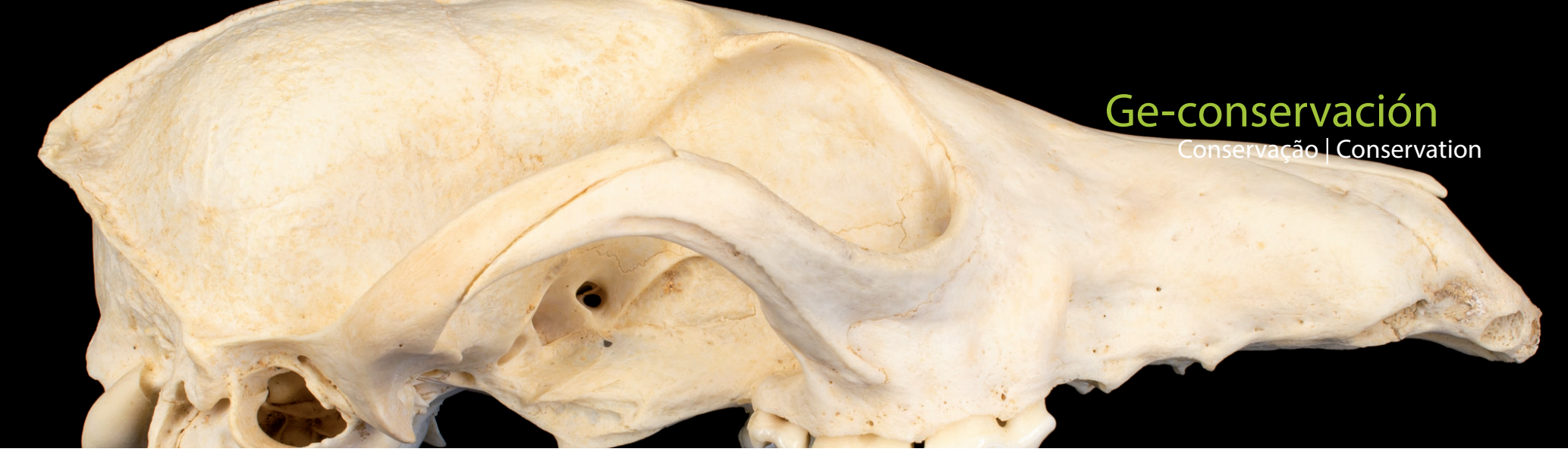

\title{
La naturaleza del hueso y su fosilización. La Tafonomía para el estudio del estado de conservación del hueso arqueológico y paleontológico
}

\author{
Andrea Díaz-Cortés, Lucía López-Polín, Héctor Del Valle, Isabel Cáceres
}

\begin{abstract}
Resumen: El hueso es un material que aparece frecuentemente en las colecciones de patrimonio cultural y especialmente en las colecciones arqueológicasy paleontológicas. Una correcta diagnosis de su estado de conservación es esencial, sin embargo, la información sobre su naturaleza y las transformaciones que se producen en ellos durante el enterramiento no es muy conocida en los trabajos de conservación. Esto hace que en muchas ocasiones el hueso sea un material desconocido en cuanto a su naturaleza. La Tafonomía se encarga de describir los agentes, procesos y efectos que afectan al hueso en los yacimientos arqueológicos o paleontológicos hasta el momento de su descubrimiento. Ello hace que las propiedades fisicoquímicas del material óseo se modifiquen, aspecto que se debe tener en cuenta en los estudios de conservación y restauración. En este trabajo se describirán distintas características del hueso, agentes que lo modifican y procesos de degradación con el objetivo de exponer un apropiado planteamiento de la naturaleza inicial, estado de conservación y adecuación de tratamientos para este material.
\end{abstract}

Palabras clave: hueso arqueológico, fósil, conservación, colágeno, bioapatita, Pleistoceno, Tafonomía

\section{The nature of bone and its fossilization. Taphonomy for the study of the conservation status of archaeological and paleontological bone}

Abstract: Bone is a frequent material in cultural heritage collections, and especially on archaeological and paleontological collections. A correct diagnosis of the state of conservation is crucial, however, the characteristic of these bones and the kind of transformations during the burial time is not well extended in conservation studies. The lack of works leads to expose the bone as an exclusively organic material, but this interpretation occasionally is not quite accurate. Taphonomy is the discipline that describes the agents, processes, and effects related to the formation of an archaeological or paleontological bone until its discovery. All these processes transform the physiochemical properties of these bones which is crucial for the study of their conservation and restoration. This work describes several characteristics of the bones, the modifying factors, and decaying mechanisms with the aim of exposing an accurate approach of nature, state of conservation which allows adapting the conservation treatments on these materials.

Keywords: archaeological bone, fossil, conservation, collagen, bioapatite, Pleistocene, Taphonomy

\section{A natureza do osso e sua fossilização. Tafonomia para o estudo do estado de conservação do osso arqueológico e paleontológico}

Resumo: O osso é um material que aparece frequentemente nas coleções de património cultural e especialmente nas coleções arqueológicas e paleontológicas. Um diagnóstico correto do seu estado de conservação é essencial, no entanto, a informação sobre a sua natureza e as transformações que se produzem neles durante o enterramento não é muito conhecida nos trabalhos de conservação. Isto faz com que muitas vezes o osso seja um material desconhecido quanto à sua natureza. A Tafonomia encarrega-se de descrever os agentes, processos e efeitos que afetam o osso nos sítios arqueológicos ou paleontológicos até ao momento da sua descoberta. Isto faz com que as propriedades físico-químicas do material ósseo sejam alteradas, o que deve ser tido em conta nos estudos de conservação e restauro. Este trabalho deve descrever diferentes características do osso, agentes modificadores e processos de degradação, com o objetivo de expor uma abordagem adequada da natureza inicial, estado de conservação e adequação de tratamentos para este material. 


\section{Introducción}

El tejido óseo es uno de los materiales más frecuentes en yacimientos arqueológicos y paleontológicos, apareciendo en todo tipo de cronologías. Solo por este hecho, la naturaleza de los huesos es variable, ¿tiene las mismas características un hueso humano perteneciente a la guerra civil española que un hueso de hominino de hace 1.000 .000 de años?

Normalmente, en manuales y programas formativos de conservación y restauración los materiales arqueológicos se dividen entre orgánicos e inorgánicos (de la Baume 1990; Cronyn 2003; García Fortes y Flos Travieso 2008). Esta separación es muy importante, ya que cada material requiere unas determinadas pautas para su conservación. En general, se asume que los fósiles de vertebrados son materiales inorgánicos de cronologías muy antiguas, por ejemplo, los dinosaurios y, por el contrario, los huesos arqueológicos se consideran materiales orgánicos de cronologías recientes (Behrensmeyer 2020). Pero esta distinción es más complicada en el caso de los restos óseos del Pleistoceno (ca. 2,58 Ma-12 ka B.P) porque corresponde a un periodo intermedio entre cronologías antiguas $y$ cronologías más modernas: ¿a qué podemos llamar fósil? ¿hay un límite de edad para diferenciar entre reciente y antiguo? Y, sobre todo, ¿la composición del material óseo dependerá de la cronología?

En muchas ocasiones aparece un tercer término que intenta solucionar este problema, el "subfósil". No obstante, su definición es ambigua, ya que puede tener diferentes significados. Por ejemplo, algunos autores, atendiendo a la cronología, afirman que los subfósiles serían aquellos que tienen menos de 13.000 años, refiriéndose, así, sobre todo a la Prehistoria reciente (García-Viñas et al. 2014), mientras que otros utilizan el término para referirse a todos los huesos del Pleistoceno (Andrew 1996; Larkin y Makridou 1999; BarrónOrtiz et al. 2018). Gran parte de los autores lo usan para referirse a la composición del material, utilizando subfósil para distinguir aquellos materiales que no han completado el proceso de mineralización (Nielsen-Marsh y Hedges 2000; Dumont et al. 2011; Tütken y Vennemann 2011).

En general, en los huesos más antiguos se ha producido una recristalización mineral y el material es totalmente inorgánico. Mientras que en huesos más modernos se preserva mejor tanto la parte orgánica como la inorgánica. Sin embargo, en cronologías intermedias, los huesos pueden tener composiciones muy diversas. Además, pueden darse casos de huesos relativamente modernos muy mineralizados (Smith et al. 2002). Sin duda, el tiempo es un factor clave, ya que cuanto mayor sea el tiempo de enterramiento mayor será la exposición a los agentes que puedan intervenir. Pero también es esencial el ambiente en el que permanecen estos restos hasta su descubrimiento (Nielsen-Marsh y Hedges 2000; Nielsen-Marsh et al. 2007)

Cuando hablamos de "historia material" en conservación y restauración nos referimos a todos esos procesos y acontecimientos que van desde la creación, fabricación, construcción de una obra u objeto hasta el momento actual.

En contextos arqueológicos y/o paleontológicos, la historia material del tejido óseo empezaría desde el momento de su formación durante la vida del organismo y la preservación de los huesos no dependerá exclusivamente de su antigüedad, sino de los agentes y procesos que participan en la modificación de su naturaleza. Estas transformaciones son estudiadas por la Tafonomía.

La Tafonomía se ocupa de los procesos de fosilización y de la formación de los conjuntos fósiles (Fernández López 2001). Los estudios tafonómicos han sido poco difundidos en el campo de la conservación y restauración. No obstante, pueden beneficiar en gran medida el conocimiento sobre la naturaleza y el deterioro de los restos óseos, y además guiarnos en la estrategia de intervención para su conservación y restauración.

Para comprender la naturaleza del hueso como orgánica o inorgánica partiremos de las características de los huesos "in vivo"y, junto con los principios de la Tafonomía, conoceremos cómo se modifican durante la fosilización. De este modo, con este trabajo incorporaremos los principios de esta disciplina en la Conservación y Restauración de cara a realizar una correcta diagnosis de su estado de preservación mediante nuevos métodos y técnicas analíticas para, además, adecuar los tratamientos a las características de estos huesos.

\section{Características del hueso}

La composición del hueso está descrita en multitud de referencias bibliográficas, distinguiendo, como ya hemos comentado, una fracción mineral y otra orgánica (Currey 2002; Collins et al. 2002; Reiche, Vignaud y Menu 2002; Turner-Walker 2007, entre otros). El porcentaje de fracción orgánica presente en un hueso fresco actual está en torno al 20-30\% y en torno un $10 \%$ de agua (Wopenka y Pateris 2005). Dentro de esta parte orgánica, un $90 \%$ corresponde a colágeno tipo I junto al $10 \%$ de proteínas no colágenas, lípidos, $A D N$ y agua, predominando en su mayor parte las fibras de colágeno. Estas fibras rodean la parte mineral, la bioapatita. La parte inorgánica corresponde a un $60-70 \%$ y se compone principalmente de bioapatita, que se deposita sobre las fibras de colágeno. La bioapatita se ha caracterizado como hidroxiapatita carbonatada no estequiométrica, $\mathrm{Ca}_{10}-{ }_{x}\left[\left(\mathrm{PO}_{4}\right)_{6}-{ }_{x}\left(\mathrm{CO}_{3}\right)\right](\mathrm{OH})_{2}-{ }^{-} \cdot \mathrm{nH}_{2} \mathrm{O}$, que contiene impurezas como carbonatos o diversos iones, que ayudan a estabilizar su cristalinidad fisiológica. Los análisis mineralógicos han expuesto que en el hueso nunca hay hidroxiapatita pura. Según Weiner (2010) se debería reservar este término para el hidroxiapatito geológico, utilizando mejor el término bioapatita para el componente mineral del hueso.

Así, la nanoestructura de los huesos está conformada por la combinación de cristales de bioapatita y fibrillas de colágeno. Estas fibrillas se pueden empaquetar al azar, en 
paralelo, dispuestas en láminas o en combinación de los anteriores (Villagran et al. 2017). En el sistema Harvesiano, estas fibras se disponen en capas concéntricas formando un canal, conocido como osteón u osteona [Figura 1]. El osteón es un cilindro que discurre normalmente en paralelo al eje largo del hueso denso de las diáfisis de los huesos largos. El hueso esponjoso, por otro lado, está formado por la interconexión de unas estructuras llamadas trabéculas (Rho, Kuhn-Spearing y Zioupos 1998; Currey 2002).

Las características específicas de cada tipo de hueso determinarán en gran parte cómo será su preservación. Para empezar, los huesos presentan una morfología muy variable, a partir de la cual se clasifican como largos, planos o articulares. A nivel de macroestructura se distinguen dos tipos de tejido: compacto y esponjoso [Figura 2]. Además, los huesos largos (e.g. fémur) presentan una zona central con un tejido más compacto (diáfisis) que corresponde a la cavidad medular y dos extremos formados en su interior por material esponjoso o trabecular (epífisis), que corresponden a las articulaciones [Figura 3]. Los huesos planos (e.g. costillas, pelvis) están formados por un tejido esponjoso interno con unas paredes compactas y finas y no tienen cavidad medular. Los huesos articulares (e.g. carpales) están formados, sobre todo, por tejido esponjoso. Los tejidos esponjosos, al ser más porosos, son susceptibles de alterarse con mayor facilidad que los tejidos compactos.

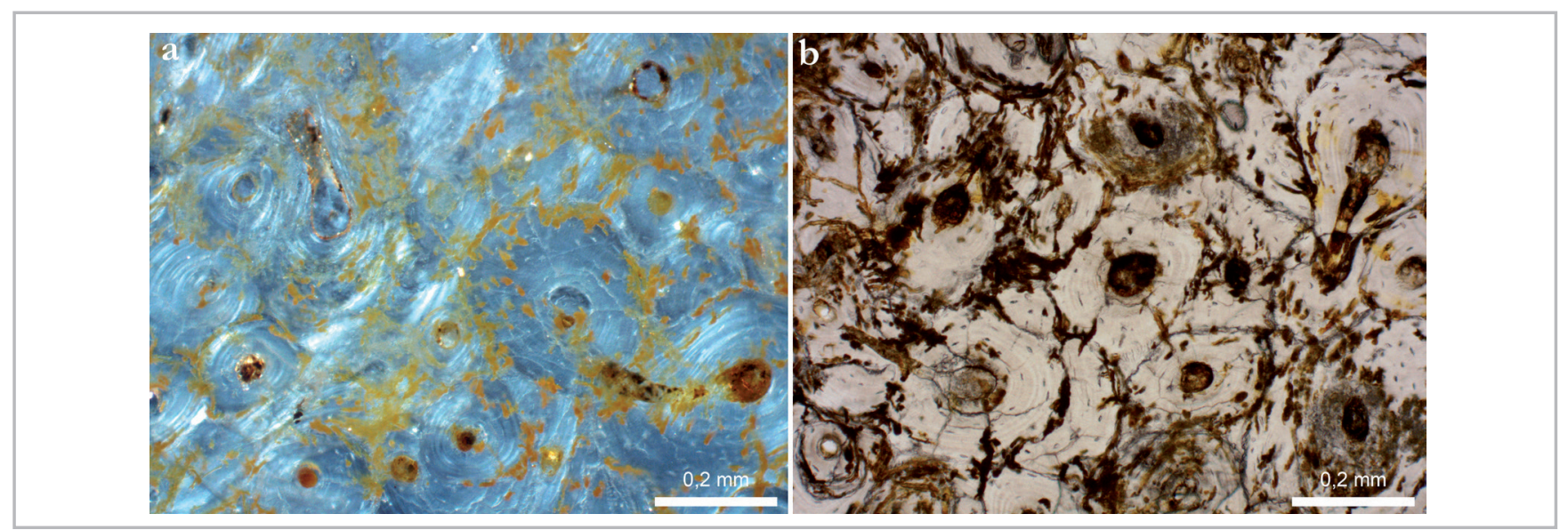

Figura 1.- Lámina histológica en la que se observan los osteones de la sección transversal de la diáfisis de un fémur de Mamuthus meridionalis del Barranc de la Boella, La Canonja, Tarragona. a) Luz polarizada cruzada (XPL). b) Luz polarizada plana PPI .

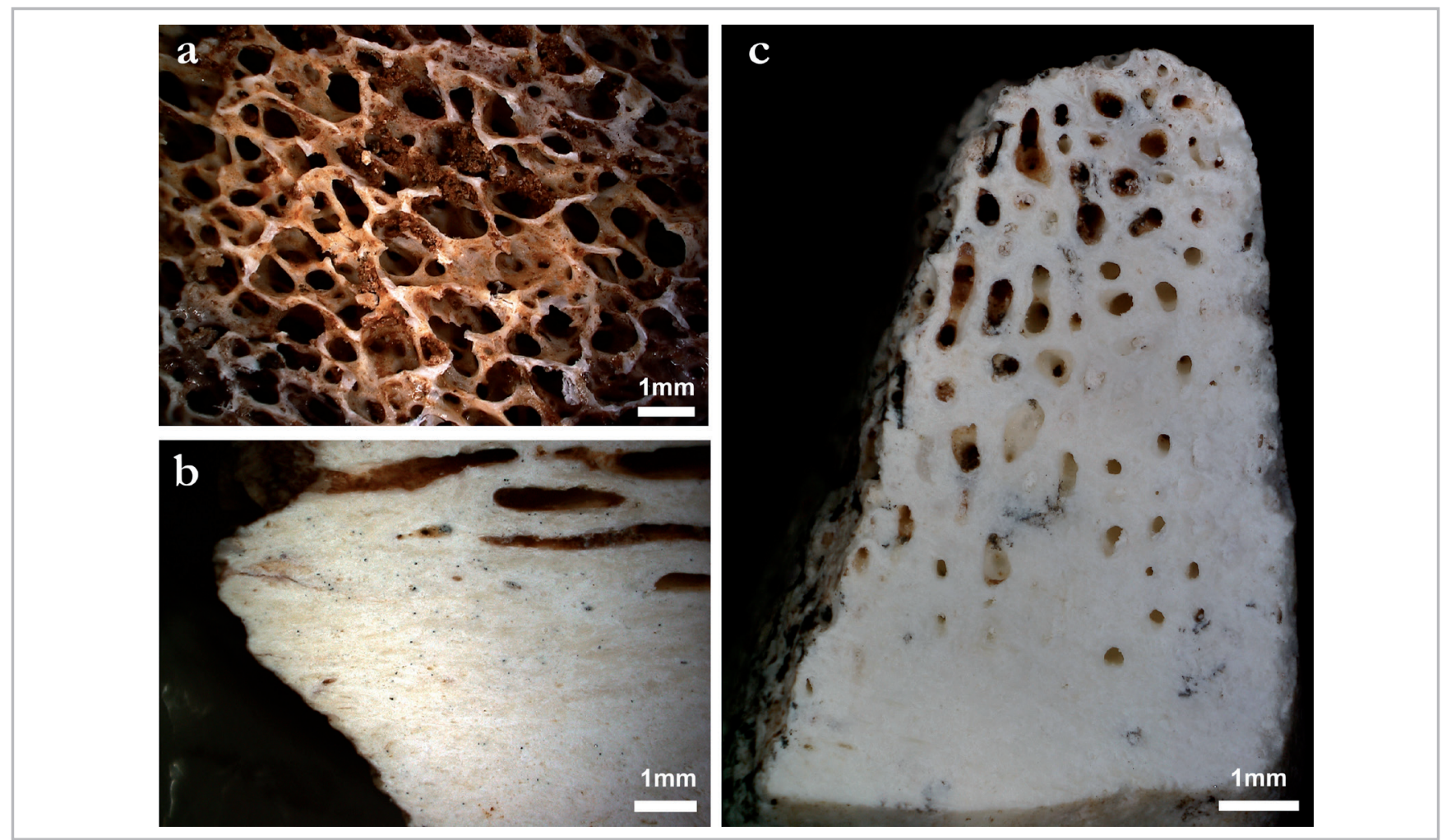

Figura 2.- Imágenes tomadas con un microscopio digital (HIROX-KH8700) de cortes transversales de diferentes huesos. a) Tejido esponjoso. b) Hueso compacto. c) Hueso que presenta ambos tejidos. 


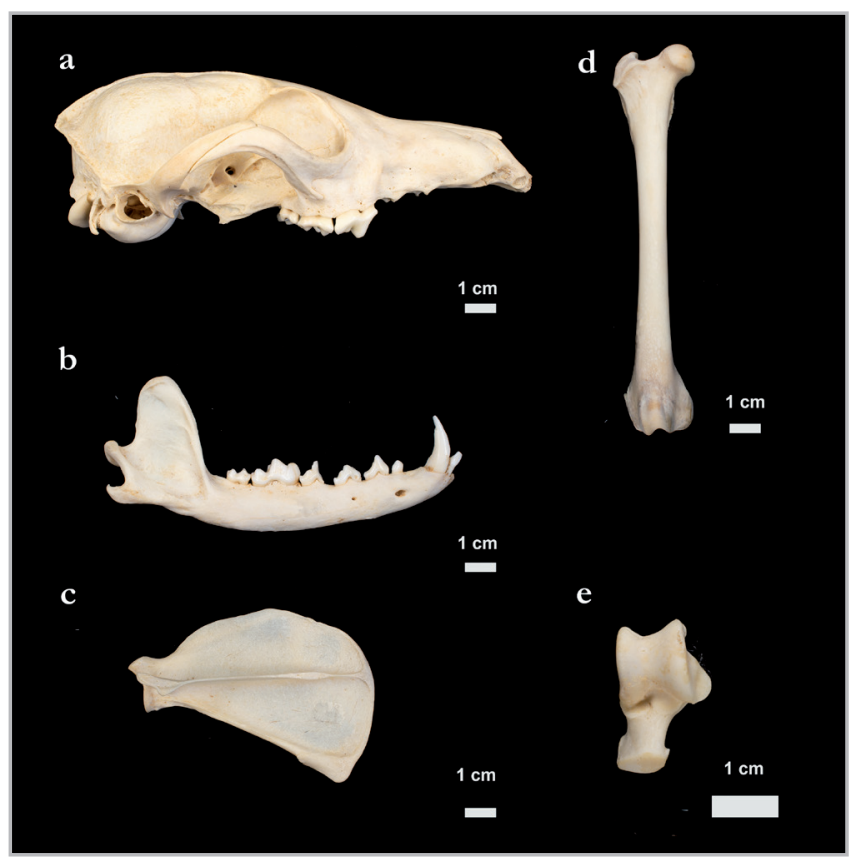

Figura 3.- Huesos pertenecientes a un individuo masculino de Vulpes vulpes. a) Cráneo b) Mandíbula c) Escápula d) Fémur e) Astrágalo.

Así, aspectos como el tamaño y el tipo de elemento anatómico, su densidad ósea, el taxón o la edad del espécimen son factores que también determinarán el grado de vulnerabilidad ante determinados agentes modificadores (Von Endt y Ortner 1984; Walker, Johnson y Lambert 1988).

\section{Historia tafonómica: la historia material}

La Tafonomía es una disciplina que estudia la transición de los organismos de la biosfera a la litosfera (Efremov 1940), por lo que abarca el periodo desde el momento de la muerte del individuo a su enterramiento final. El estudio tafonómico se aplica, no sólo a los organismos, sino también a las evidencias de su actividad. Buen ejemplo de ello pueden ser los coprolitos (heces fósiles) o las astas de cérvido, fruto del desmogue, [Figura 4] no implicando necesariamente la muerte de los individuos (Fernández López 2000, 2001)

Cuando se aplica al Pleistoceno, la metodología tafonómica juega un papel importante para conocer el comportamiento de los grupos humanos, el rol de otros predadores o los procesos naturales que, como los agentes atmosféricos, puedan afectar a la conservación de los restos óseos.

La Tafonomía distingue dos fases principales durante el proceso de fosilización: la bioestratinómica y la fosildiagenética [Figura 5]. La primera incluye todas las modificaciones que se producen en el hueso desde la muerte o producción del animal hasta su enterramiento, mientras que la fase fosilidiagenética recoge todas las modificaciones que suceden después del enterramiento. Sin embargo, estas fases no pueden entenderse de manera lineal, es decir, estas dos etapas no tienen por qué ser consecutivas o unidireccionales. El hueso puede desenterrarse, lo cual se define como reelaboración, o no haber estado expuesto nunca a procesos bioestratinómicos (Fernández López 2000). En cada una de estas fases pueden intervenir diversos agentes tafonómicos y se pueden desarrollar mecanismos que favorecerán o no la preservación de los restos.

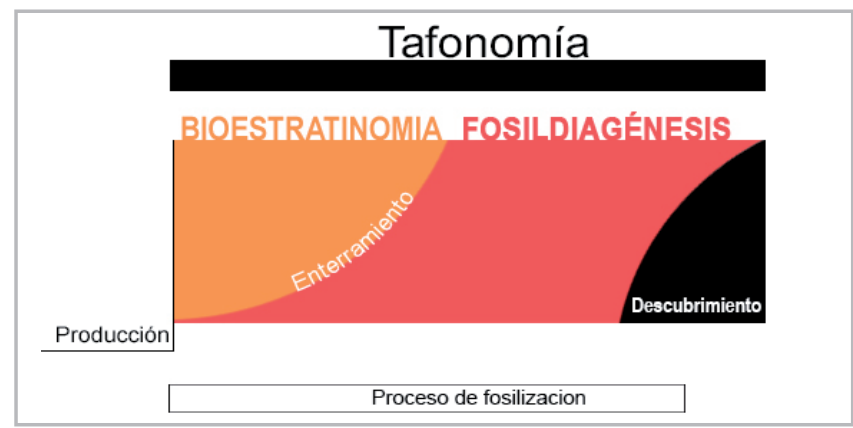

Figura 5.- Esquema conceptual de la Tafonomía basado en Fernández López, S. (2000) pp. 116.

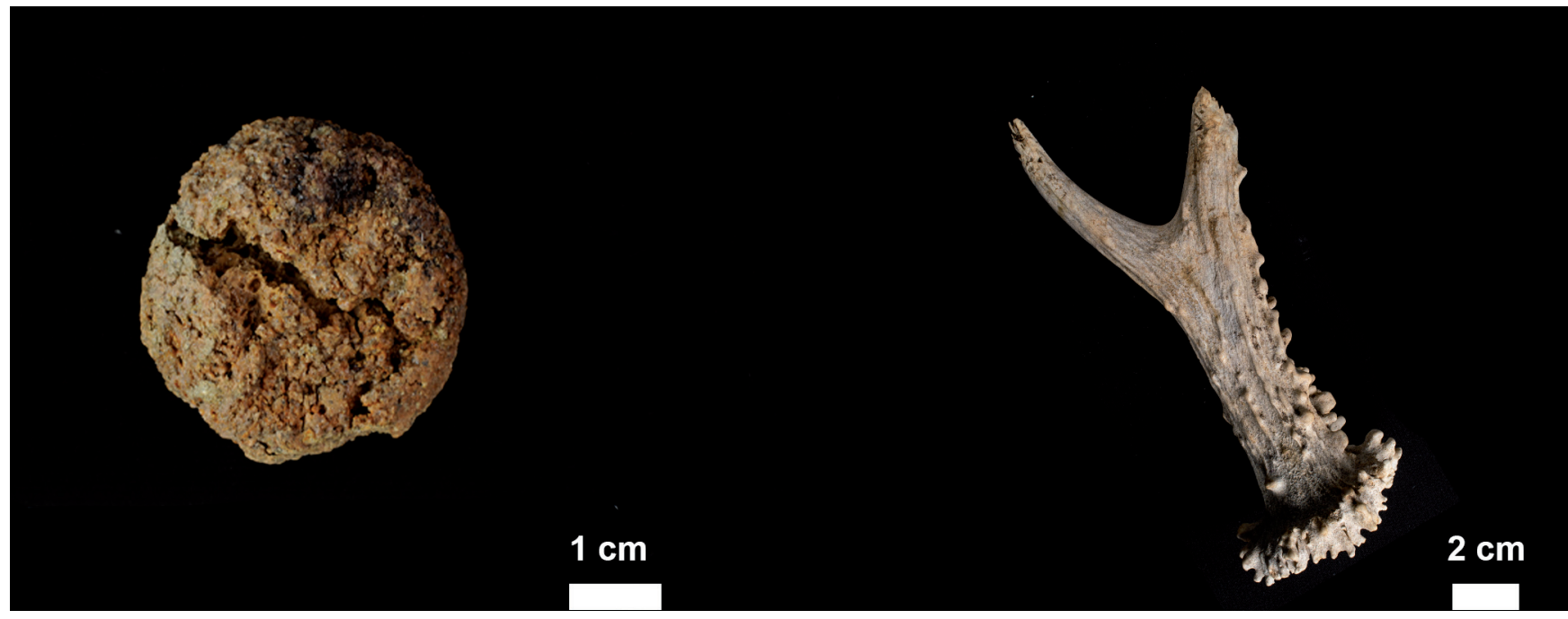

Figura 4.- Imágenes de un coprolito de hiena (izquierda) perteneciente al yacimiento del Barranc de la Boella (La Canonja, Tarragona) y un resto de asta de corzo (derecha) actual de desmogue. 


\section{-Bioestratinomía}

En la fase bioestratinómica se producen sesgos tafonómicos severos y ello determinará qué restos se enterrarán y serán, por tanto, susceptibles de fosilizar. En esta fase pueden intervenir agentes de naturaleza diversa y las modificaciones que se producen se pueden clasificar en bióticas, es decir, las producidas por seres vivos, o abióticas, las producidas por agentes naturales.

\section{Modificaciones bióticas}

En este grupo se encuentran las modificaciones producidas por los humanos y las modificaciones producidas por otros animales, como los carnívoros o los roedores. Las modificaciones antrópicas están relacionadas con el proceso de carnicería (despellejamiento, descarnación, desarticulación, etc.) es decir, con el procesamiento y consumo de todos los nutrientes animales (carne, médula, grasa, sangre) y de las partes no consumibles pero sí aprovechables con fines tecnológicos, como son la piel, los tendones o los huesos (Lyman 1994; Fernández-Jalvo, Cáceres y Marín-Monfort 2013). Entre esas modificaciones destacan las marcas de corte, que se producen por el contacto del filo de la herramienta con la superficie de hueso, y los golpes, desconchados y fracturas producidos para acceder a la médula [Figura 6.a]. Los carnívoros utilizan su dentición y producen señales (surcos y depresiones) en los huesos cuando arrancan la carne, por lo que el tamaño de esas mordeduras y su localización nos ayudará a conocer el tipo de carnívoro que las produjo [Figura 6.b]. Los roedores roen los huesos para desgastar sus dientes de crecimiento continuo o para obtener sales minerales en caso de dietas empobrecidas, produciendo señales acanaladas en los bordes de los restos [Figura 6.c].

\section{Termoalteración}

Entre las modificaciones que producen los humanos, la termoalteración tiene especial interés para la restauración. Esta se puede producir durante el cocinado de alimentos (asado o hervido) (Roberts et al. 2002), o, posteriormente, por cremaciones intencionales de tipo funerario o como forma de limpieza de espacios domésticos.

En cualquier caso, esta alteración produce cambios de coloración, agrietamientos, fragmentación y deformaciones a nivel macroscópico (Shipman, Foster y Schoeninger 1984; Nicholson 1993; Stiner et al. 1995; Surovell y Stiner 2001; Cáceres 2002; Lebon 2010). Los cambios de coloración se ven fuertemente influidos por el estado del hueso (fresco o seco) y el contexto de la termoalteración (en brasas, enterrados, semienterrados)(Pérez et al. 2017).

Desde un punto de vista microscópico, la termoalteración produce una recristalización de los cristales de bioapatita y una hidrólisis acelerada del colágeno y los componentes
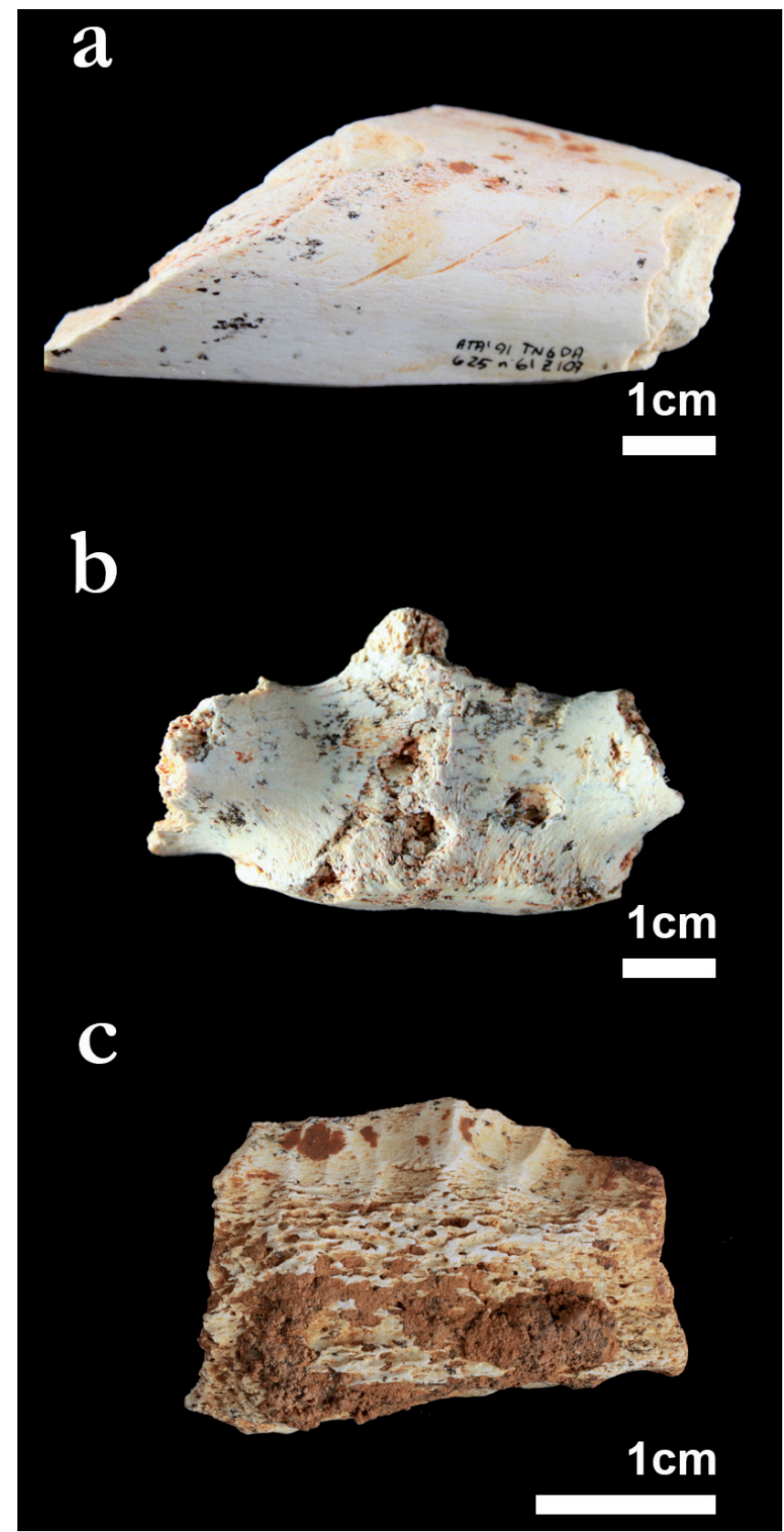

Figura 6.- Ejemplo de modificaciones tafonómicas de origen biótico procedentes del yacimiento de Galería (Sierra de Atapuerca, Burgos). a) marcas de corte en un fémur de ciervo; b) mordeduras de carnívoro en un sacro de ciervo; c) fragmento indeterminado con evidencias de roído.

orgánicos (Lebon etal. 2008; Thompson etal. 2011; Ellingham, Thompson y Islam 2016; Del Valle y Cáceres 2020).

\section{Modificaciones abióticas}

Entre las modificaciones abióticas más recurrentes en el registro arqueológico podemos encontrar el weathering o meteorización y la abrasión hídrica.

La meteorización, en inglés weathering, es la exposición de los restos a los agentes atmosféricos, a los cambios de temperatura y humedad $\mathrm{y}$, principalmente, a la acción 
de los rayos UVA, que produce agrietamientos, fisuras y pérdida de tejido en los huesos (Behrensmeyer 1978; Tuross 1989; Fernández-Jalvo, Cáceres y Marín-Monfort 2013; Fernández-Jalvo y Andrews 2016). Estas fisuras iniciales pueden desarrollarse y provocar la fragmentación y total desintegración del hueso [Figura 7a]. Asimismo, los procesos de hielo/deshielo (gelifracción), también pueden generar agrietamientos (Guadeli 2008) contribuyendo, por tanto, a producir cambios en la composición de estos huesos.

La meteorización provoca un descenso de los niveles de colágeno y una rotura de sus fibras, exponiendo la parte inorgánica a procesos de disolución y recristalizaciones que supone un aumento del tamaño de los cristales (White y Hannus, 1983; Tuross et al., 1989; Trueman et al., 2004).

Otra modificación a tener en cuenta es la abrasión hídrica, que puede provocar redondeamiento y pulido de los huesos, dependiendo del tiempo de exposición a la alteración, de la velocidad de la corriente hídrica, del tipo de sedimento que contiene el agua y del estado del hueso (fresco, seco, meteorizado, fósil) cuando se somete a la alteración (Fernández-Jalvo, 2003; Pineda et al., 2019). Esta alteración produce además pérdida de morfología y puede obliterar otras modificaciones.

\section{—Fosildiagénesis}

Dentro de la fase fosildiagenética hay diversos agentes y procesos que pueden modificar los diferentes niveles de la estructura de los huesos. Una modificación habitual en los contextos arqueológicos y/o paleontológicos es la dejada por las raíces de las plantas [Figura 7.b], que producen surcos irregulares y reticulares cuando se introducen en los huesos en busca de contenido mineral (Gabet, Reichman y Seabloom 2003; Pokines y Baker 2013). Sin embargo, las principales modificaciones fosildiagenéticas se producen por el intercambio mineral entre el hueso y el sedimento durante el proceso de fosilización (Lyman 1994).

Hedges y colegas propusieron en 1995 una serie de parámetros diagenéticos para caracterizar el estado de conservación de un hueso arqueológico: la preservación histológica, el contenido de colágeno, la cristalinidad y la porosidad. En estudios posteriores, se amplió el conocimiento de estos parámetros diagenéticos para saber qué mecanismos se producen y cuáles son sus causas (Hedges y Millard 1995; Nielsen-Marsh y Hedges 1999; Nielsen-Marsh y Hedges 2000; Hedges 2002). Gracias a estos estudios se han descrito los procesos que derivan en la degradación, tanto de la parte orgánica como de la inorgánica, que explicaremos a continuación.

\section{a.- Degradación de la parte inorgánica}

La fracción inorgánica es especialmente susceptible a los ambientesácidos,llegandoencasosextremosasudisolución. Entre otros autores, Nielsen Marsh y colaboradores (2007) exponen que en los suelos con un pH bajo la supervivencia del hueso es muy difícil. El pH en el que se conservan los huesos está en un rango de 7-8. Algunos autores especifican que sería entre 7.8 y 8.1 (Berna, Matthews y Weiner 2004). Sin

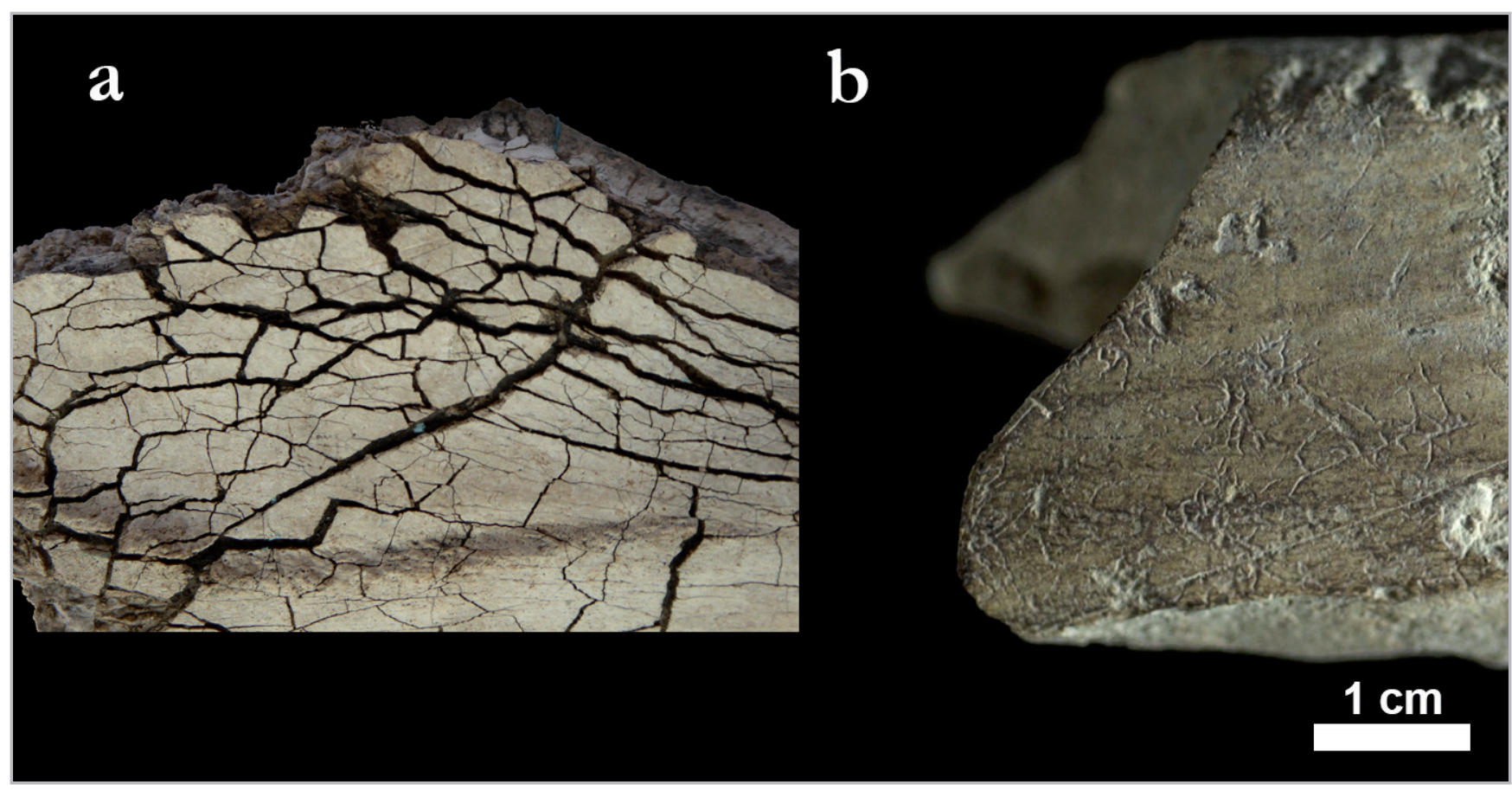

Figura 7.- a) Agrietamientos producidos por weathering o meteorización en una mandíbula de bóvido procedente del yacimiento de Gona (Región Afar, Etiopía) ; b) Tibia de ciervo procedente del yacimiento del Abric Romaní (Capellades, Barcelona) con marcas producidas por raíces. 
embargo, con un $\mathrm{pH}$ entre 7-8 puede haber disoluciones y reprecipitaciones de la bioapatita mineral. Por tanto, para que se produzca un cambio en la naturaleza del hueso, el medio no necesariamente tiene que ser ácido $(\mathrm{pH}<7)$, sino que puede ser neutro o ligeramente básico.

Boethius y colaboradores (2020) publicaron un estudio sobre los restos óseos del yacimiento mesolítico sueco Ageröd I, recuperados en diferentes campañas: en las décadas de los 40, 70 y en 2019. En este tiempo, los cambios producidos por las excavaciones han desembocado en una progresiva acidificación del sedimento, se han acelerado los mecanismos de deterioro, y los restos óseos presentan diferentes estados de conservación dependiendo del momento de su excavación. Hay, incluso, zonas con un pH entre 4.2 y 5 en las que el hueso está ausente del todo. Este estudio muestra que, en un periodo corto, de 75 años, el $\mathrm{pH}$ puede cambiar y provocar la pérdida de los restos óseos.

Si bien ya se considera el agua como un importante agente bioestratinómico, en la fosildiagénesis tiene un mayor poder modificador (Hedges y Millard 1995; Berna Matthews y Weiner 2004). Hedges y Millard (1995) hablan principalmente de tres regímenes hidrológicos: difusivo, recarga y fluido. Los medios difusivos corresponden a ambientes en los que el agua es permanente o, por el contrario, en los que está ausente. En este tipo de contextos suele favorecerse la preservación del material óseo (Grupe 1995). Por el contrario, en medios de recarga y fluido puede haber ciclos de humectación y secado. Los minerales del hueso están sujetos a su disolución lo que provoca el intercambio con iones externos $\mathrm{Ca}^{+2}, \mathrm{PO}_{4}{ }^{-3} \mathrm{O} \mathrm{CO}_{3}{ }^{-2}$.

\section{b.- Degradación de la parte orgánica}

Collinsetal.(1995) proponen un modelo de degradación del colágeno a partir de procesos de hidrólisis que producen las rupturas de los enlaces peptídicos de la proteína [Figura 8]. Estos autores exponen que la solubilización del colágeno provoca el aumento de la porosidad, cavidades que se llaman "colágeno fantasma". La rapidez de su eliminación puede depender de si el mecanismo es químico o de si hay presencia de microorganismos (Collins et al. 2002).

Mediante estudios histológicos se ha observado que la actividad de los microorganismos produce una bioerosión que consiste en la disminución de la materia orgánica y el incremento de la porosidad, con la presencia de túneles (Piepenbrink 1986; Trueman y Martill 2002; Jans et al. 2004; Turner-Walker y Jans 2008). Estos túneles pueden producirse tanto por bacterias como por hongos, además de por otros organismos como las cianobacterias (Huisman et al. 2017).

La actividad de microorganismos, que también puede darse en la fase bioestratinómica (Child 1995; Collins et al. 2002; Trueman et al. 2004), puede desarrollarse en un tiempo relativamente breve, algunos autores lo
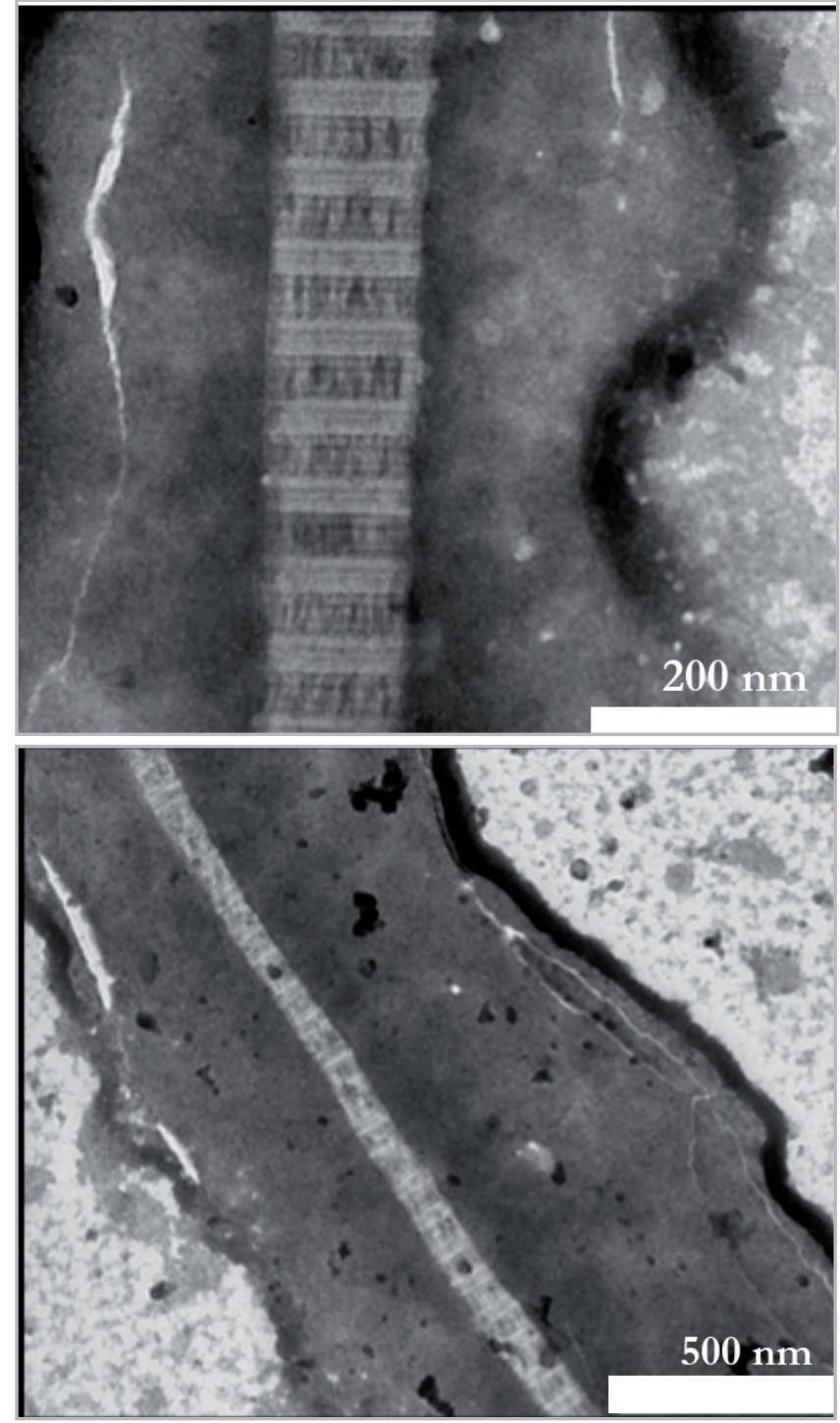

Figura 8.- Detalle de una fibra de colágeno en un hueso actual (Del Valle y Cáceres 2020).

fijan en menos de 500 años (Hedges 2002). Existe una relación entre la intensidad de los ataques de estos microorganismos, el ambiente y el estado del hueso. Por ejemplo, muchos autores han puntualizado que, para que se produzca un ataque biológico sobre el colágeno del hueso, previamente se debe producir un cambio en la matriz cristalina; esto permite que las enzimas que segregan los microorganismos puedan penetrar por esta matriz para llegar a la proteína. En las zonas donde se ha producido la actividad microbiana, además de la pérdida de materia orgánica, también es característico que se produzcan disoluciones y redistribuciones de la bioapatita (Turner-Walker y Syversen 2002).

Otras biomoléculas presentes en el hueso, como la osteocalcina, se estabilizan con la fracción mineral dada su naturaleza similar. En menor medida pueden preservarse algunos lípidos como el colesterol, que puede ser una fuente de análisis para estudios isotópicos (Collins et al. 2002). Para el ADN mismo, hay una proliferación de 
bibliografía sobre la posibilidad de una pervivencia longeva de este material genético, si bien la degradación es similar a la del colágeno (Kendall et al. 2018; Kontopoulos et al. 2019). Aunque es complicado, hay algunas excepciones como la reciente secuenciación del genoma de un mamut de más de un millón de años conservado en permafrost, el material genético más antiguo hasta el momento (van der Valk et al. 2021).

\section{- Trayectorias diagenéticas}

En 2007 se publicaron dos trabajos en los que se expusieron, por primera vez, cuatro posibles trayectorias diagenéticas de los restos, directamente relacionadas con la preservación de los huesos, y los indicadores a tener en cuenta para su identificación (Nielsen-Marsh et al. 2007; Smith et al. 2007). Si bien, estos trabajos sólo se aplicaron al ambiente templado europeo han devenido en investigaciones de referencia a nivel global. Una trayectoria corresponde con la buena conversación del hueso, mientras que las otras tres corresponden a diferentes caminos de degradación ósea. Cabe destacar que en las tres se produce pérdida de colágeno, ya sea por hidrólisis acelerada, por disolución o por ataque bacteriano [Tabla 1].

\section{La naturaleza del hueso: un viaje hacia lo inorgánico}

En este trabajo se han recopilado algunos de los procesos que pueden afectar a las características del hueso durante su fosilización. En resumen, los

\begin{tabular}{|c|c|c|c|c|c|}
\hline \multicolumn{2}{|c|}{ Parámetros diagenéticos } & $\begin{array}{l}\text { Tipo } 1 \\
\text { Buena } \\
\text { preservación }\end{array}$ & $\begin{array}{c}\text { Tipo } 2 \\
\text { Hidrólisis } \\
\text { acelerada de } \\
\text { colágeno }\end{array}$ & $\begin{array}{c}\text { Tipo } 3 \\
\text { Hueso con } \\
\text { ataque } \\
\text { microbiológico }\end{array}$ & $\begin{array}{c}\text { Tipo } 4 \\
\text { Disolución } \\
\text { catastrófica } \\
\text { mineral }\end{array}$ \\
\hline \multicolumn{2}{|c|}{$\begin{array}{l}\text { wt } \% \text { Colágeno } \\
\text { Cantidad de colágeno }\end{array}$} & & & & \\
\hline \multicolumn{2}{|c|}{$\begin{array}{c}\text { Índice de cristalinidad (IRSF) } \\
\text { Infrarred Spliting factor en }{ }_{v 4}\left(\mathrm{PO}_{4}\right) \text { en el pico } 567 \mathrm{~cm}^{-1} \text { y } 605 \mathrm{~cm}^{-1} \\
\text { FTIR }\end{array}$} & & & & \\
\hline \multicolumn{2}{|c|}{$\begin{array}{l}\text { Ratio carbonato/ fosfato (C/P) } \\
\text { Índice de los picos de carbonato } 1415 \mathrm{~cm}^{-1} \text { y fosfato } 1035 \mathrm{~cm}^{-1} \\
\text { FTIR }\end{array}$} & & & & \\
\hline \multicolumn{2}{|c|}{$\begin{array}{l}\text { Índice histológico Oxford (OHI) } \\
\text { Estudio de la cantidad de destrucción en una sección transver- } \\
\text { sal del hueso }\end{array}$} & & 口 & & च \\
\hline \multicolumn{2}{|c|}{$\begin{array}{l}\text { Índice de ruptura } \\
\text { Cantidad de estructuras básicas (osteonas) incompletas }\end{array}$} & & & 㞋 & 口 \\
\hline \multirow{3}{*}{$\begin{array}{l}\text { Porosidad } \\
\text { Porosimetría de Mercurio } \\
\text { (MIP) }\end{array}$} & $\begin{array}{c}\mathrm{S} \\
\text { Poro: }>0.01 \mu \mathrm{m}<0.1 \mu \mathrm{m}\end{array}$ & & & & \\
\hline & $\begin{array}{c}M \\
\text { Poro: }>0.1 \mu \mathrm{m}<8.5 \mu \mathrm{m}\end{array}$ & & & & \\
\hline & $\begin{array}{c}\mathrm{L} \\
\text { Poro: }>8.5 \mu \mathrm{m} 70 \mu \mathrm{m}\end{array}$ & & & & \\
\hline \multicolumn{2}{|c|}{$\begin{array}{l}\text { Densidad aparente (Bulk density) } \\
\text { Densidad incluyendo volumen intersticial y volumen de poros } \\
\text { abiertos y cerrados }\end{array}$} & & & & \\
\hline \multicolumn{2}{|c|}{$\begin{array}{l}\text { Densidad real (Skeletal density) } \\
\text { Densidad excluyendo el volumen de poros conectados }\end{array}$} & & & & \\
\hline
\end{tabular}

Tabla 1.- Parámetros diagenéticos utilizados para identificar los 4 tipos de preservación en material óseo descritos por Smith et al (2007) 
procesos bioestratinómicos como la termoalteración, la meteorización o la abrasión hídrica, pueden afectar a la composición fisicoquímica del hueso. Sin embargo, procesos como la intervención de carnívoros o de humanos no condicionan las características químicas de los huesos.

En cuanto a los procesos fosildiagenéticos, factores como el agua, el pH o la presencia de microorganismos, produce, de manera general, la degradación de la parte orgánica, con la pérdida de colágeno y la transformación de la parte inorgánica dando como resultado la recristalización de la bioapatita. La degradación de una fracción puede condicionar la preservación de la otra, siendo evidente una disminución de la fracción orgánica a lo largo del enterramiento.

Sin embargo, llama la atención que en el ámbito de la conservación y restauración este material se incluya directamente en el tipo orgánico, con todo lo que eso implica para la toma de decisiones de su tratamiento y conservación (Cronyn 2003; García Fortes y Flos Travieso 2008). Hablar sobre los huesos como un material que se comporta como material orgánico y generalizar sobre su sensibilidad ante los cambios de humedad ambiental puede ser incorrecto en muchos casos. La composición que se describe, normalmente, es la de un hueso actual ("vivo"), obviándose que ya no forma parte de un organismo vivo y que diversos procesos tafonómicos han podido convertirlo en un material cada vez más inorgánico.

En algún trabajo se ha descrito el hueso como un material higroscópico, sensible a cambios de humedad relativa (Bouzas Abad y Laborde Marqueze 2002). Sin embargo, Turner-Walker (2007) expone que los huesos arqueológicos (exceptuando aquellos saturados en agua) son relativamente inertes y estables dimensionalmente ante cambios bruscos de humedad.

\section{Consideraciones finales}

Son escasos los trabajos en el ámbito de la conservación que expongan la naturaleza del hueso sumando la amplitud cronológica, los diversos contextos sedimentarios, factores de alteración y estado de preservación. La Tafonomía es la disciplina especializada en el estudio de los procesos implicados en la fosilización $y$, por tanto, sus principios pueden servir para introducir descripciones estandarizadas del estado de preservación de estos huesos y clasificar las alteraciones.

Es fundamental desarrollar una diagnosis correcta del material y alejarnos de la imagen simple del hueso como material orgánico olvidando el proceso de fosilización y la transformación de su naturaleza. De tal manera que para la descripción del estado de preservación de estos huesos serían esenciales las siguientes dos fases:
1. El análisis tafonómico superficial que permite identificar las alteraciones tafonómicas acaecidas, tanto en la fase bioestratinomica (marcas antrópicas, carnívoros, meteorización, abrasión hídrica etc.) como en la fosildiagenética (actividad de raíces, influencia del $\mathrm{pH}$, etc.). Así, se determinar los agentes, procesos y mecanismos que se produjeron a lo largo del proceso de fosilización.

2. El análisis microestructural a través de técnicas como la DRX o FTIR-ATR permite conocer la degradación, tanto de la fracción orgánica como de la inorgánica. De este modo, describir el aumento de la porosidad, la disminución de materia orgánica o el incremento de la cristalinidad permite unificar las descripciones de las características fisicoquímicas y el estado de preservación de los huesos.

En definitiva, aunque los trabajos sobre la conservación y restauración del hueso arqueológicos y/o paleontológico no presente un nivel de desarrollo comparable al de otros bienes culturales, como serían monumentos, metales, etc., los estudios tafonómicos, especialmente, los relacionados con la fosildiagénesis, pueden fomentar una mejor compresión y descripción de su naturaleza. De este modo, será posible desarrollar una diagnosis correcta para este tipo de material y alejarnos de la imagen simple de que el hueso pertenece al grupo de materiales orgánicos.

\section{Agradecimientos}

Este trabajo ha sido posible gracias a la financiación de varios proyectos, entre ellos PGC2018-093925-B-C32 (MICINNFEDER), SGR 2017-1040 (AGAUR), 2019PFR-URV-91 (URV) y CLT009/18/00053 (Generalitat de Catalunya). Las investigaciones desarrolladas en el IPHES se enmarcan en el programa CERCA. Dicha investigación está apoyada por el Ministerio de Ciencia e Innovación de España a través de la acreditación de excelencia "María de Maeztu" (CEX2019-000945-M). ADC goza de una beca FPU (FPU17-05506) financiada por el Ministerio de Ciencia, Innovación y Universidades.

\section{Referencias}

ANDREW, K. (1996). "A summary of the care and preventative conservation of sub-fossil bone for the non-specialist or pleistocene problems -The sub-fossil scenario", The biology curator, 5: 24-28.

BARRÓN-ORTIZ, C. et al. (2018). "Conservation of subfossil bones from a lacustrine setting: Uncontrolled and controlled drying of late quaternary vertebrate remains from cold lake, western Canada", Collection Forum, 32(1): 1-13. https://doi. org/10.14351/0831-4985-32.1.1

BEHRENSMEYER, A. K. (1978). "Taphonomic and ecologic information from bone weathering", Paleobiology, 4(2): 150-162. https://doi.org/10.2307/2400283. 
BEHRENSMEYER, A. K. (2020). "Taphonomy", Reference Module in Earth Systems and Environmental Sciences, 1-11. https://doi. org/10.1016/b978-0-08-102908-4.00120-x.

BERNA, F.; MATTHEWS, A. ; WEINER, S. (2004). "Solubilities of bone mineral from archaeological sites: The recrystallization window", Journal of Archaeological Science, 31(7): 867-882. https://doi. org/10.1016/j.jas.2003.12.003.

BOETHIUS, A. et al. (2020). "Human encroachment, climate change and the loss of our archaeological organic cultural heritage: Accelerated bone deterioration at Ageröd, a revisited Scandinavian Mesolithic key-site in despair", PLOS ONE, 15(7): 1-23. https://doi.org/10.1371/journal.pone.0236105.

BOUZAS ABAD, A.; LABORDE MARQUEZE, A. (2002). "La degradación del hueso", Monte Buciero, 9: 267-275.

CÁCERES, I. (2002). Tafonomía de yacimientos antrópicos en karst. Complejo Galería (Sierra de Atapuerca, Burgos), Vanguard Cave (Gibraltar) y Abric Romaní (Capellades, Barcelona). Universidad Rovira i Virgili.

CHILD, A. M. (1995). “Towards and understanding of the microbial decomposition of archaeological bone in the burial environment", Journal of Archaeological Science, 22(2): 165-174. https://doi. org/10.1006/jasc.1995.0018.

COLLINS, M J. et al. (2002). "Bone Diagenesis: implications for heritage management", en 9th ICAZ Conference, 124-132.

COLLINS, M. J. et al. (2002). "The survival of organic matter in bone: A review", Archaeometry, 44(3): 383-394. https://doi. org/10.1111/1475-4754.t01-1-00071.

CRONYN, J. M. (2003). Elements of Archaeological Conservation. Routledge. London. https://doi.org/10.2307/1506325.

CURREY, J. (2002). "The structure of bone tissue", en Bones: structure and mechanics. Princeton, 224-225. https://doi.org/ $\underline{10.1515 / 9781400849505 .}$.

DAL SASSO, G. et al. (2016). "Bone diagenesis variability among multiple burial phases at Al Khiday (Sudan) investigated by ATR-FTIR spectroscopy", Palaeogeography, Palaeoclimatology, Palaeoecology. Elsevier B.V., 463: 168-179. https://doi. org/10.1016/j.palaeo.2016.10.005.

DEL VALLE, H.; CÁCERES, I. (2020). "Los efectos del hervido en la microestructura ósea. Estado de la cuestión y enfoques metodológicos para su caracterización en el registro arqueológico", ArkeoGazte, 10: 261-275.

DUMONT, M. et al. (2011). "Size and size distribution of apatite crystals in sauropod fossil bones", Palaeogeography, Palaeoclimatology, Palaeoecology, 310(1-2): 108-116. https://doi. org/10.1016/j.palaeo.2011.06.021.

EFREMOV, J. A. (1940). "Taphonomy: new branch of paleontology", American Geologist, 74: 81-93.
ELLINGHAM, S. T. D.; THOMPSON, T. J. U.; ISLAM, M. (2016). “The Effect of Soft Tissue on Temperature Estimation from Burnt Bone Using Fourier Transform Infrared Spectroscopy", Journal of Forensic Sciences, 61(1): 153-159. https://doi.org/10.1111/15564029.12855.

VON ENDT, D. W.; ORTNER, D. J. (1984). "Experimental effects of bone size and temperature on bone diagenesis", Journal of Archaeological Science, 11(3): 247-253. https://doi. org/10.1016/0305-4403(84)90005-0.

FERNÁNDEZ-JALVO, Y.; Andrews, P (2003). "Experimental effects of water abrasion on bone fragments", Journal of taphonomy, 1(3): 145-161.

FERNÁNDEZ-JALVO, Y.; CÁCERES, I.; MARÍN-MONFORT, M. D. (2013). “Tafonomía", en Garcia-Diez, M. y Zapata, L. (eds.) Métodos y técnicas de análisis y estudio en la arqueología prehistórica. De lo técnico a la reconstrucción de los grupos humanos. Universida, 367-404

FERNÁNDEZ-JALVO, Y.; ANDREWS, P. (2016). Atlas of Taphonomic Identifications. 1001+1 Images of fossil and recent mammal bone modification. Springer.

FERNÁNDEZ LÓPEZ, R. S. (2000). Temas de Tafonomía. Madrid.

FERNÁNDEZ LÓPEZ, S. R. (2001). "Tafonomía, fosilización y yacimientos de fósiles: Modelos alterenaticos", Enseñanza de Ciencias de la Tierra, 9(2): 116-120.

GABET, E. J.; REICHMAN, O. J.; SEABLOOM, E. W. (2003). "The effects of bioturbation on soil processes and sediment transport", Annual Review of Earth and Planetary Sciences, 31: 249-273. https://doi. org/10.1146/annurev.earth.31.100901.141314.

GARCÍA-VIÑAS, E. et al. (2014). “Diecinueve años de investigación sobre el patrimonio paleobiológico de la Prehistoria Reciente andaluza", pH, 86: 88-100.

GARCÍA FORTES, S.; FLOS TRAVIESO, N. (2008). Conservación y restauración de bienes arqueológicos. Sintesis. Madrid.

GRUPE, G. (1995). "Preservation of collagen in bone from dry, sandy soil", Journal of Archaeological Science, 22(2): 193-199. https://doi.org/10.1006/jasc.1995.0021.

GUADELLI, J. L. (2008). "La gélifraction des restes fauniques. Expérimentation et transfert au fossile". Annales de Paléontologie. 94: 121-165.

HEDGES, R. E. M. (2002). “Bone diagenesis: An overview of the processes", Archaeometry, 44: 319-328.

HEDGES, R. E. M.; MILLARD, A. R. (1995)."Bones and Groundwater: Towards the Modelling of Diagenetic Processes", Journal of Archaeological Science. Academic Press, 22(2): 155-164. https:// doi.org/10.1006/JASC.1995.0017. 
HEDGES, R. E. M.; MILLARD, A. R.; PIKE, A. W. G. (1995) "Measurements and relationships of diagenetic alteration of bone from three archaeological sites", Journal of Archaeological Science, 22(2): 01-209. https://doi.org/10.1006/jasc.1995.0022.

HUISMAN, H. et al. (2017). "Micromorphological indicators for degradation processes in archaeological bone from temperate European wetland sites", Journal of Archaeological Science. Elsevier Ltd, 85: 13-29. https://doi.org/10.1016/j. jas.2017.06.016.

JANS, M. M. E. et al. (2004). "Characterisation of microbial attack on archaeological bone", Journal of Archaeological Science, 31: 8795. https://doi.org/10.1016/j.jas.2003.07.007.

KENDALL, C. et al. (2018). "Diagenesis of archaeological bone and tooth", Palaeogeography, Palaeoclimatology, Palaeoecology. Elsevier, 491: 21-37. https://doi.org/10.1016/j.paleo.2017.11.041.

KONTOPOULOS, I. et al. (2019). "Petrous bone diagenesis: a multi-analytical approach", Palaeogeography, Palaeoclimatology, Palaeoecology. Elsevier, 518: 143-154. https://doi.org/10.1016/j. palaeo.2019.01.005.

DE LA BAUME, S. (1990). “Les matériaux organiques", en Berdecou, M. C. (ed.) La conservation en Achéologie Méthodes et practique de la conservation-restauration des vestigues archélogiques. Masson. Paris, 220-270.

LARKIN, N. R.; MAKRIDOU, E. (1999). “Comparing gap-fillers used in conserving sub-fossil material", Geological curators group, 7(2): 81-91.

LEBON, M. et al. (2008). "Characterization of archaeological burnt bones: Contribution of a new analytical protocol based on derivative FTIR spectroscopy and curve fitting of the $v 1 v 3$ PO4 domain", Analytical and Bioanalytical Chemistry, 392(7-8): 14791488. https://doi.org/10.1007/s00216-008-2469-y.

LEBON, M. (2010). "The taphonomy of burned organic residues and combustion features in archaeological contexts", Palethnologie, 2: 145-158.

LEBON, M. et al. (2016). "Rapid quantification of bone collagen content by ATR-FTIR spectroscopy", Radiocarbon, 58(1), pp. 131145. https://doi.org/10.1017/RDC.2015.11.

LYMAN, R. L. (1994). Vertebrate Taphonomy. Cambdridge University Press. https://doi.org/10.1017/CBO9781139878302.

NICHOLSON, R. A. (1993). "A morphological investigation of burnt animal bone and an evaluation of its utility in archaeology", Journal of Archaeological Science, 411-428. https://doi. org/10.1006/jasc.1993.1025.

NIELSEN-MARSH, C. M.; HEDGES, R. E. M. (1999). "Bone porosity and the use of mercury intrusion porosimetry in bone diagenesis studies", Archaeometry, 41(1): 165-174. https://doi. org/10.1111/j.1475-4754.1999.tb00858.x.
NIELSEN-MARSH, C M.; HEDGES, R. E. M. (2000). "Patterns of diagenesis in bone I: The effects of site environments", Journal of Archaeological Science, 27(12): 1139-1150. https://doi. org/10.1006/jasc.1999.0537.

NIELSEN-MARSH, C.M.; HEDGES, R. E. M. (2000). "Patterns of diagenesis in bone II: Effects of acetic acid treatment and the removal of diagenetic CO 32", Journal of Archaeological Science, 27(12): 1151-1159. https://doi.org/10.1006/jasc.1999.0538.

NIELSEN-MARSH, C. M. et al. (2007). "Bone diagenesis in the European Holocene II: taphonomic and environmental considerations", Journal of Archaeological Science, 34(9): 15231531. https://doi.org/10.1016/j.jas.2006.11.012.

PÉREZ, L. et al. (2017). "Hearths and bones: An experimental study to explore temporality in archaeological contexts based on taphonomical changes in burnt bones", Journal of Archaeological Science: Reports. Elsevier Ltd, 11: 287-309. https:// doi.org/10.1016/j.jasrep.2016.11.036.

PIEPENBRINK, H. (1986). "Two examples of biogenous dead bone decomposition and their consequences for taphonomic interpretation", Journal of Archaeological Science, 13(5): 417-430. https://doi.org/10.1016/0305-4403(86)90012-9.

PINEDA, A. et al. (2019). "Tumbling effects on bone surface modifications (BSM): An experimental application on archaeological deposits from the Barranc de la Boella site (Tarragona, Spain)", Journal of Archaeological Science. Elsevier, 102: 35-47. https://doi.org/10.1016/j.jas.2018.12.011.

POKINES, J. T.; BAKER, J. E. (2013). “Effects of Burial Environment on Osseus Remains", en Manual of Forensic Taphonomy. CRC Press, 73-114.

REICHE, I., VIGNAUD, C.; MENU, M. (2002). "The crystallinity of ancient bone and dentine: New insights by transmission electron microscopy", Archaeometry, 44(3): 47-459. https://doi.org/ 10.1111/1475-4754.00077.

RHO, J. Y., KUHN-SPEARING, L.; ZIOUPOS, P. (1998). "Mechanical properties and the hierarchical structure of bone", Medical Engineering and Physics, 20(2): 92-102. https://doi.org/10.1016/ S1350-4533(98)00007-1.

ROBERTS, S. J. et al. (2002). "The taphonomy of cooked bone: characterizing boiling and its physico-chemical effects", Archaeometry, 44(3): 485-494. https://doi.org/10.1111/14754754.t01-1-00080.

SHIPMAN, P., FOSTER, G. Y SCHOENINGER, M. (1984) “Burnt bones and teeth: an experimental study of color, morphology, crystal structure and shrinkage", Journal of Archaeological Science, 11 (4: 307-325. https://doi.org/10.1016/0305-4403(84)90013-X.

SMITH, C. I. et al. (2002). "The strange case of Apigliano: early "fossilization" of medieval bone in southern Italy", Archaeometry, 44(3): 405-415. https://doi.org/10.1111/1475- 


\section{4.t01-1-00073.}

SMITH,C.I. etal. (2007).“Bone diagenesis in the European Holocene I: patterns and mechanisms", Journal of Archaeological Science, 34(9): 1485-1493. https://doi.org/10.1016/j.jas.2006.11.006.

STINER, M. C. et al. (1995). "Differential Burning, Recrystallization, and Fragmentation of Archaeological Bone", Journal of Archaeological Science, 22: 223-237. https://doi.org/10.1006/ jasc.1995.0024.

SUROVELL, T. A.; STINER, M. C. (2001). "Standardizing infrared measures of bone mineral crystallinity: An experimental approach", Journal of Archaeological Science, 28(6): 633-642. https://doi.org/10.1006/jasc.2000.0633.

THOMPSON, T. J. U. et al. (2011). “An investigation into the internal and external variables acting on crystallinity index using Fourier Transform Infrared Spectroscopy on unaltered and burned bone", Palaeogeography, Palaeoclimatology, Palaeoecology. Elsevier B.V., 299(1-2): 168-174. https://doi.org/10.1016/j.palaeo.2010.10.044.

TRUEMAN, C. N.; MARTILL, D. M. (2002). “The long-term survival of bone: the role of bioerosion", Archaeometry, 44(3): 371-382. https://doi.org/10.1111/1475-4754.t01-1-00070.

TRUEMAN, C. N. G. et al. (2004). "Mineralogical and compositional changes in bones exposed on soil surfaces in Amboseli National Park, Kenya: Diagenetic mechanisms and the role of sediment pore fluids", Journal of Archaeological Science, 31(6): 721-739. https://doi.org/10.1016/j.jas.2003.11.003.

TURNER-WALKER, G. (2007). "Degradation pathways and conservation strategies for ancient bone from wet anoxic sites", Proceedings of the 10th ICOM Group on Wet Organic Archaeological Materials Conference: Amsterdam 2007, (September 2007), 659675.

TURNER-WALKER， G.; SYVERSEN， U. (2002). "Quantifying histological changes in archaeological bones using BSE-SEM image analysis", Archaeometry, 44(3): 461-468. https://doi. org/10.1111/1475-4754.t01-1-00078.

TURNER-WALKER, G. Y JANS, M. (2008) "Reconstructing taphonomic histories using histological analysis", Palaeogeography, Palaeoclimatology, Palaeoecology, 266: 227235. https://doi.org/10.1016/j.palaeo.2008.03.024.

TUROSS, N. (1989). "Albumin preservation in the Taima-taima mastodon skeleton", Applied Geochemistry, 4(3): 255-259. https:// doi.org/10.1016/0883-2927(89)90026-7.

TUROSS, N. et al. (1989). "Molecular preservation and crystallographic alterations in a weathering sequence of wildebeest bones", Applied Geochemistry, 4(3): 261-270. https:// doi.org/ 10.1016/0883-2927(89)90027-9.

TÜTKEN, T.; VENNEMANN, T. W. (2011). "Fossil bones and teeth: Preservation or alteration of biogenic compositions?",
Palaeogeography, Palaeoclimatology, Palaeoecology, 310(1-2): 1-8. https://doi.org/10.1016/j.palaeo.2011.06.020.

VAN DER VALK, T. et al. (2021). "Million-year-old DNA sheds light on the genomic history of mammoths", Nature, 591: 265-269. https:// doi.org/10.1038/s41586-021-03224-9.

VILLAGRAN, X. S.et al. (2017). "Bone annd other skeletal tissues", en Nicosia, C. y Stoops, G. (eds.) Archaeological soil and sediment micromorphology. Wiley Blac, 11-38.

WALKER, P. L., JOHNSON, J. R. ; LAMBERT, P. M. (1988). "Age and sex biases in the preservation of human skeletal remains", American Journal of Physical Anthropology, 76(2), 183-188. https://doi. org/10.1002/ajpa.1330760206.

WEINER, S. (2010). Microarchaeology: beyond the Visible Archaeological Record. Cambridge. https://doi.org/10.1017/ CBO9780511811210.

WHITE, E. ; HANNUS, L. A. (1983). “Chemical weathering of bone in archaeological soils", Society for American Archaeology, 48(2): 316322. https://doi.org/10.2307/280453.

WOPENKA, B.; PASTERIS, J. D. (2005). "A mineralogical perspective on the apatite in bone", Materials Science and Engineering C, 25(2): 131-143. https://doi.org/10.1016/j.msec.2005.01.008.

\section{Autor/es}

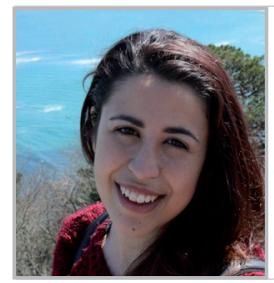

Andrea Díaz Cortés
adiaz@iphes.cat
Institut Català de Paleoecologia Humana i
Evolució Social (IPHES-CERCA). Universitat
Rovira i Virgili (URV)
https://orcid.org/0000-0002-5629-4226

Graduada en Conservación y Restauración del Patrimonio Cultural en la Universidad Complutense de Madrid en 2015. En 2017 finalizó el Máster en Diagnóstico del Estado de Conservación del Patrimonio histórico de la Universidad Pablo de Olavide (UPO) y en 2019 el Master Erasmus Mundus en Arqueología de Cuaternario y Evolución Huma de la Universitar Rovira i Virgili. Desde 2018 realiza su tesis doctoral a través de un contrato predoctoral FPU financiado por el Ministerio de Ciencia, Innovación y Universidades en el Institut Català de Paleocologia i Evolució Social (IPHES). El principal objetivo de esta tesis es la evaluación de la consolidación en hueso arqueológico comparando tanto productos orgánicos como las resinas acrílicas, como productos inorgánicos (nanocales, DAP, etc), enfocándolo en los yacimientos de la Sierra de Atapuerca (Burgos) y Barranc de la Boella (Tarragona). Ha colaborado como conservadora-restauradora en el Museo Arqueológico Regional de Madrid, y desde 2016 participa en las campañas de excavación de los yacimientos de Sierra de Atapuerca así como en otros yacimientos arqueológicos del Pleistoceno en España. 


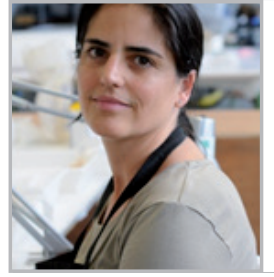

\section{Lucía López-Polín}

lucia.lopezpolin@iphes.cat

Institut Català de Paleoecologia Humana i Evolució Social (IPHES-CERCA). Universitat Rovira i Virgili (URV)

https://orcid.org/0000-0002-5810-4115

Con una larga trayectoria profesional como conservadorarestauradora de material arqueológico, desarrollada especialmente en el marco de proyectos de investigación en arqueología prehistórica. Su tesis doctoral fue sobre los criterios y métodos de intervención aplicados a los fósiles de homínidos de la Gran Dolina (Sierra de Atapuerca). Autora de numerosas publicaciones y contribuciones a congresos, ha impartido también diversos cursos sobre restauración arqueológica. Actualmente continúa trabajando como restauradora, así como desarrollando labores docentes y de investigación en conservación y restauración.

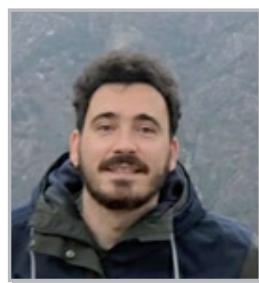

\author{
Héctor Del Valle Blanco \\ hectorvalleblanco@gmail.com \\ Universitat Rovira i Virgili (URV). Institut \\ Català de Paleoecologia Humana $i$ \\ Evolució Social (IPHES-CERCA) \\ https://orcid.org/0000-0003-4363-8082
}

Graduado en Arqueología por la Universidad Complutense de Madrid en 2016. En 2018 finalizó el Máster Erasmus Mundus en Arqueología del Cuaternario y Evolución Humana en la Universitat Rovira i Virgili (URV) con estancia en el museo Museo Nacional de Historia Natural de París. En 2021 finalizó el máster en Genética, Química y Física forense en la URV. Actualmente, trabaja como técnico de apoyo a la investigación en el Institut catalá de Paleoecología Humana i Evolució Social (IPHES). Su investigación se dirige al análisis tafonómico con especialización en técnicas bioquímicas, microscópicas y macroscópicas para el estudio de restos óseos desde una perspectiva de la diagénesis ósea. Desde 2015 participa en varios proyectos y campañas de excavación arqueológica como Atapuerca (Burgos, España) o el proyecto Arrels (Queralbs, Girona).

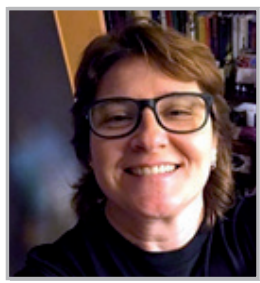

\section{Isabel Cáceres Cuello de Oro \\ icaceres@iphes.cat \\ Universitat Rovira i Virgili (URV). Institut \\ Català de Paleoecologia Humana $\mathrm{i}$ \\ Evolució Social (IPHES-CERCA). \\ http://orcid.org/0000-0001-8487-2591}

Doctora por la Universitat Rovira i Virgili (URV) en el año 2002. Investigadora docente de esta universidad y del Institut Català de Paleoecología Humana i Evolució Social (IPHES) en Tarragona. Como docente imparte la asignatura de Prehistoria de la Península Ibérica en el grado de Historia y la asignatura de Tafonomía y Zooarqueología en el Máster de Arqueología del Cuaternario y Evolución Humana (URV). Especialista en Tafonomía, estudia las estrategias de subsistencia de los grupos humanos del pleistoceno. Ha participado en múltiples proyectos de excavación e investigación de yacimientos de la Península ibérica, así como en África y en el Cáucaso. Entre ellos, destaca su participación en los yacimientos de la Sierra de Atapuerca (Burgos, España), donde desde 2011 coordina los trabajos de excavación e investigación del yacimiento Galería (Pleistoceno Medio). Dirigió el proyecto de excavación del sitio de la Cueva de Azokh (Cáucaso Medio) entre 2009 y 2011. Desde 2013, coordina las investigaciones tafonómicas desarrolladas en los sitios pleistocenos de Gona (Etiopía) y Ain Hanech y Tighennif (Argelia), analizando las relaciones entre los primeros homininos y la explotación de los recursos faunísticos. Es autora de más de 100 artículos científicos y ha participado en una cincuentena de congresos y seminarios nacionales e internacionales.

Artículo enviado el 25/05/2021 Artículo aceptado el 22/09/2021 (c) $\underset{\mathrm{BY}}{(} \mathrm{NC}_{\mathrm{ND}}$

https://doi.org/10.37558/gec.v20i1.1001 